\title{
Metabolic and Scintigraphic Studies of Radioiodinated Human C-reactive Protein in Health and Disease
}

\author{
David M. Vigushin, Mark B. Pepys, and Philip N. Hawkins \\ Immunological Medicine Unit, Department of Medicine, Royal Postgraduate Medical School, \\ Hammersmith Hospital, London W12 ONN, United Kingdom
}

\begin{abstract}
Plasma and whole-body turnover studies of human C-reactive protein (CRP), isolated from a single normal healthy donor and labeled with ${ }^{125} \mathrm{I}$, were undertaken in 8 healthy control subjects and 35 hospitalized patients including cases of rheumatoid arthritis, systemic lupus erythematosus, infections, and neoplasia. Plasma clearance of ${ }^{125}$ I-CRP closely approximated to a monoexponential function and was similar in the control and all patient groups. There was no evidence for accelerated clearance or catabolism of CRP in any of the diseases studied. The 19-h half-life was more rapid than that of most human plasma proteins studied previously, and the fractional catabolic rate was independent of the plasma CRP concentration. The synthesis rate of CRP is thus the only significant determinant of its plasma level, confirming the validity of serum CRP measurement as an objective index of disease activity in disorders associated with an acute-phase response. Approximately $90 \%$ of injected radioactivity was recovered in the urine after $7 \mathrm{~d}$, and scintigraphic imaging studies with ${ }^{123}$ I-labeled CRP in 10 patients with different focal pathology showed no significant localization of tracer. The functions of CRP are thus likely to be effected predominantly in the fluid phase rather than by major deposition at sites of tissue damage or inflammation. (J. Clin. Invest. 1993. 90:1351-1357.) Key words: C-reactive protein • metabolism • plasma protein • scintigraphy • turnover studies
\end{abstract}

\section{Introduction}

C-reactive protein $(\mathrm{CRP})^{1}$ is the classical acute phase plasma protein, serum levels of which are extensively used in routine clinical practice to monitor the acute phase response, and therefore the extent and activity of many infections, tissue damaging and inflammatory disorders (1). Along with serum amyloid $\mathrm{P}$

This work has been presented in part at meetings of the Royal Society of Medicine in December 1991 and the British Society for Rheumatology in July 1992, and at the Third International Conference on Systemic Lupus Erythematosus, London, United Kingdom, April 1992.

Address correspondence to Dr. P. N. Hawkins, Immunological Medicine Unit, Royal Postgraduate Medical School, London W12 0NN, United Kingdom.

Received for publication 17 August 1992 and in revised form 27 October 1992.

1. Abbreviations used in this paper: $\mathrm{AA}$, amyloid A protein; $\mathrm{AL}$, monoclonal light chain amyloid; CRP, C-reactive protein; PAF, platelet-activating factor; SAP, serum amyloid $P$ component.

J. Clin. Invest.

(C) The American Society for Clinical Investigation, Inc.

0021-9738/93/04/1351/07 \$2.00

Volume 91, April 1993, 1351-1357 component (SAP), CRP is a member of the pentraxin family of proteins which are unrelated to other known proteins, but which are themselves stably conserved in vertebrate evolution (2). No polymorphism of either the gene coding sequence or of the protein itself has been described in man, nor has any individual lacking CRP been identified, suggesting that CRP has an important biological role. This may be related to specific binding of CRP to phosphocholine-containing molecules including plasma lipoproteins, cell membrane phospholipids, microbial products and phospholipid mediators, such as platelet-activating factor (PAF) $(3,4)$. Contrary to some reports $(5,6)$, human CRP does not bind to chromatin under physiological conditions $(7,8)$ but it does bind avidly and specifically to small nuclear ribonucleoprotein particles within whole nuclei (9).

Binding of CRP to soluble and particulate ligands can opsonise them for phagocytissis, predominantly via the classical complement pathway which complexed or aggregated CRP activates with high efficiency $(10,11)$. There is also some evidence for the existence of receptors for CRP on the surface of polymorphs and monocyte/macrophages, and it has been claimed that CRP and/or its fragments have functional activity in modifying the behaviour of these cells (11-14). Heterologous, human, CRP protects mice against pneumococcal infection $(15,16)$ but there is no evidence for a similar protective role of autologous CRP, for example, in the human or the rat (3), or for human CRP in mice with other infections. Thus, although the many different properties of CRP which have been described suggest that it may contribute to lipid metabolism, scavenging and repair of damaged cells and tissues, host defence against infection and modulation of inflammation, no definite in vivo functions of CRP have yet been identified.

In normal healthy subjects CRP is a trace plasma protein with a median level of $0.8 \mathrm{mg} /$ liter (17). It is produced by hepatocytes in which its synthesis is regulated by cytokines, particularly IL-6 ( 18). CRP levels rise rapidly and dramatically in response to bacterial infection, trauma, tissue necrosis, and most forms of inflammation, and may exceed $300 \mathrm{mg} /$ liter within $48 \mathrm{~h}$ of an acute event $(1,2)$. High levels may persist indefinitely in chronic inflammatory states. In contrast, there are a few important disorders, particularly systemic lupus erythematosus (SLE) and related collagen diseases, ulcerative colitis, and leukemia, in which CRP levels usually remain normal, or are only modestly elevated, even in the presence of severe tissue damaging pathology $(1,2)$. The mechanisms underlying this phenomenon are not known, though affected individuals retain the capacity to develop a typical major acute phase reaction in response to intercurrent microbial infection or tissue infarction $(1,2)$.

The isolation of pure CRP from the plasma of a single normal healthy individual, which we report here, has enabled us to study the in vivo distribution and metabolism of human CRP in health and in various diseases, including rheumatoid arthritis (RA), SLE, bacterial infection, and neoplasia. 


\section{Methods}

Isolation of CRP. Highly purified human CRP was prepared by calcium-dependent affinity chromatography, reverse affinity chromatography and gel filtration $(19,20)$, from 10 liters of serum from a single accredited normal donor to the British National Blood Transfusion Service. The serum was first heated to $56^{\circ} \mathrm{C}$ for $30 \mathrm{~min}$, which is known to inactivate human immunodeficiency virus (21). The yield of $8 \mathrm{mg}$ of sterile nonpyrogenic CRP consisted exclusively of intact pentameric CRP molecules as shown by analytical gel filtration on Superose 12 (Pharmacia Biosystems Ltd., Milton Keynes, UK) and nondenaturing 4-30\% gradient PAGE (Pharmacia). It was $>99 \%$ pure in reduced SDS 10\% PAGE and was fully functionally active in terms of calciumdependent binding to phosphoethanolamine-Sepharose. Analysis by electrospray mass spectrometry (22) yielded a single species of mass $23,027 \mathrm{D}$, corresponding precisely to the known amino acid sequence of the CRP subunit $(23,24)$ including the amino-terminal pyrrolidone carboxylic acid residue (25).

Radioiodination of CRP. CRP was oxidatively radiolabeled with carrier-free ${ }^{125}$ I (IMS.30; Amersham International, Amersham, UK) and ${ }^{123}$ I (Medgenix, Fleurus, Belgium) using $N$-bromosuccinimide (26, 27 ), and resulting in $85-95 \%$ incorporation of the isotope. Free unbound radioiodine was removed by gel filtration on Sephadex G25 (PD10 column; Pharmacia), and the labeled protein was then passed through a sterile $0.22-\mu \mathrm{m}$ filter into a sterile nitrogen-filled vial. The specific activity of ${ }^{125} \mathrm{I}-\mathrm{CRP}$ used for turnover studies was $37 \mathrm{MBq} / \mathrm{mg}$; for gamma camera imaging and localization studies, ${ }^{123}$ I-CRP was labeled with a specific activity of $5 \mathrm{GBq} / \mathrm{mg}$. Greater than $95 \%$ of the activity was shown to be protein bound by precipitation with cold $10 \%$ wt/vol TCA.

Characterization of iodinated CRP. The iodinated CRP was sterile and non-pyrogenic in rabbits. It was structurally and functionally indistinguishable from pure CRP in nondenaturing gradient PAGE, reduced SDS-PAGE, gel filtration and binding to phosphoethanolamineSepharose and phosphocholine-Sepharose. The labeled CRP was also tested by comparing its in vivo plasma clearance with that of unlabeled CRP in two female CBA/Ca mice and one NZW rabbit. One mouse received a single intravenous injection of $1 \mu \mathrm{g}$ of ${ }^{125}$ I-CRP mixed with $200 \mu \mathrm{g}$ of unlabeled CRP purified from pooled malignant ascites fluid. The other mouse received $1 \mu \mathrm{g}$ of ${ }^{125} \mathrm{I}-\mathrm{CRP}$ mixed with $0.3 \mathrm{ml}$ of pooled whole acute phase serum containing $73 \mu \mathrm{g}$ of CRP. The rabbit received $5 \mu \mathrm{g}$ of ${ }^{125} \mathrm{I}-\mathrm{CRP}$ mixed with $1 \mathrm{ml}$ of pooled whole acute phase serum containing $244 \mu \mathrm{g}$ of CRP. All animals were bled at intervals after injection, the sera were separated and both the TCA-precipitable radioactivity and the human CRP concentration were measured in each sample. CRP concentration was measured by electroimmunoassay (range $2-143 \mathrm{mg} /$ liter, C.V. $<10 \%$ ) (28) in the mouse samples and by a sensitive monoclonal antibody immunoradiometric assay (range 10$5,000 \mu \mathrm{g} /$ liter, C.V. $<10 \%)(29)$ in the rabbit experiment.

${ }^{125}$ I-CRP clearance studies-experimental subjects. Eight normal healthy adult volunteers, four male and four female, aged 20-32 yr, and 33 hospitalized patients were studied. Sixteen patients had chronic inflammatory diseases: RA ( six patients), SLE ( six), other connective tissue disorders (two), systemic vasculitis (one), and Crohn's disease (one). Eleven other patients had bacterial infections: acute aspiration pneumonia (one patient), lower urinary tract infections (five), acute pyelonephritis (one), postoperative psoas abscess (one), minor cellulitis (one), and osteomyelitis (two). Finally, five patients had malignant neoplasia: bronchogenic carcinoma (two patients), multiple myeloma (one), lymphoma (one), and adenocarcinoma of unknown primary site (one).

Turnover study protocol. After excluding a history of adverse reactions to iodide, thyroid uptake of radioiodine was blocked by the prior administration of oral potassium iodide. $180 \mathrm{kBq}$ of ${ }^{125} \mathrm{I}$-CRP was administered by bolus intravenous injection, resulting in an effective dose equivalent of $0.045 \mathrm{mSv}$. Venous blood samples were drawn from the contralateral forearm at 10 -min intervals for the first $30 \mathrm{~min}$, hourly for the following $6 \mathrm{~h}$ and then daily for $7 \mathrm{~d}$. Consecutive 24-h urine collec- tions were obtained for the study period. Protein bound radioactivity in $0.5-\mathrm{ml}$ aliquots of all serum samples, and total radioactivity in $1-\mathrm{ml}$ aliquots of each 24-h urine collection were counted simultaneously with a standard aliquot of the injected material. The results were expressed as a percentage of the injected quantity per liter of serum or urine. In one normal subject and two patients with raised plasma CRP levels each whole blood sample, its clot and serum sample were counted separately in order to assess uptake of tracer by blood cells; no such uptake was detected. The total CRP concentration was measured by electroimmunoassay (28) and when necessary by immunoradiometric assay (29) in all serum samples, and all the subjects reported here had constant values throughout the period of study. Other individuals in whom serum CRP concentrations varied have been excluded from this report.

Curve fitting and metabolic analysis. Plasma activity data were fitted to a single exponential function by non-linear regression. Plasma volumes were estimated from body surface area, and calculated from the $y$-axis intersect at notional time zero. The synthesis rate for CRP was derived from the area under the curve and its biological half-life and fractional clearance rate from the value of the exponent. The whole-body retention of radioactivity was calculated at daily intervals by subtracting the cumulative activity excreted in the urine from the total injected radioactivity. Statistical significance of differences between CRP metabolism in normal controls and disease groups was sought by one way analysis of variance.

${ }^{123}$ I-CRP scintigraphic imaging studies. For imaging and localization studies CRP was labeled with ${ }^{123} \mathrm{I}$, a medium energy pure gamma emitter, which has a short half-life of $13.2 \mathrm{~h}$ and is ideally suited to in vivo scintigraphic imaging $(27,30)$. After thyroid blockade, each subject received $200 \mathrm{MBq}$ of ${ }^{123}$ I-CRP by bolus intravenous injection, resulting in an effective dose equivalent of $4 \mathrm{mSv}$, comparable to that of an intravenous pyelogram or barium series. Anterior and posterior whole body scintigraphic imaging were performed immediately after injection and at 6,24, and $48 \mathrm{~h}$ using the IGE-Starcam gamma camera (IGE Medical Systems, Slough, UK) with a medium energy parallel hole collimator. Regional views and quantitative analysis of tracer localization to liver, spleen, kidneys and other sites of interest were performed. Three female and 7 male patients, aged $26-84 \mathrm{yr}$, were studied. Four patients had malignant neoplasms: metastatic bronchogenic carcinoma (two patients), multiple myeloma and systemic AL amyloidosis (one), and retroperitoneal T cell lymphoma (one). Three patients had local infections, respectively: thoracic vertebral osteomyelitis, pneumococcal lobar pneumonia, and post-operative psoas abscess. Three patients had active idiopathic inflammatory diseases, respectively: Crohn's disease of the terminal ileum complicated by systemic AA amyloidosis, polymyositis, and SLE complicated by an intercurrent acute infective pharyngitis.

Ethical approval. All participants gave informed written consent and the project was approved by the Research Ethics Committee of Hammersmith Hospital and the Administration of Radioactive Substances Advisory Committee of the Department of Health, United Kingdom.

\section{Results}

Clearance of iodinated CRP in vivo in animals. The in vivo plasma clearance of ${ }^{125} \mathrm{I}-\mathrm{CRP}$ in mouse and rabbit was indistinguishable from that of isolated unlabeled CRP, or of CRP provided in whole acute phase serum. In mice the $t_{1 / 2}$ was $4 \mathrm{~h}$ and in the rabbit it was $7 \mathrm{~h}$, values similar to those previously reported (31-33). Together with the precise mass spectrometric confirmation of the structure of the subunits of the single donor CRP and the in vitro biochemical evidence for full structural and ligand-binding integrity of the labeled CRP, these observations establish the validity of the present preparations as in vivo tracers of CRP metabolism. 
Clearance of ${ }^{125}$ I-CRP in normal volunteers. In normal subjects there was an initial distribution phase lasting several hours during which plasma activity fell relatively rapidly. This was followed by a slower steady decline throughout the 7-d study period during which the mean (SD) plasma half-life was 18.8 (3.9) h. Plasma clearance was paralleled by whole body radioactivity with a delay of $\sim 24 \mathrm{~h}$, indicating that substantial tissue sequestration of ${ }^{125} \mathrm{I}$-CRP did not occur (Fig. 1). At $7 \mathrm{~d}$ the whole-body clearance was mean (SD) $88(6.9 \%)$ of the injected dose. Plasma ${ }^{125}$ I-CRP activity values closely approximated to a monoexponential function in all subjects. Total plasma CRP levels remained constant throughout the period of study (median $0.8 \mathrm{mg} /$ liter) enabling various metabolic parameters to be calculated. The fractional clearance rate of CRP was $92 \%$ of the plasma pool per day, and equal to the fractional catabolic rate measured directly from the cumulative urinary excretion of ${ }^{125}$ I. The synthesis rate of CRP was $\sim 2.4 \mathrm{mg} / 24 \mathrm{~h}$ and the calculated notional time zero volume of distribution was $\sim 1.4$ times greater than the plasma volume estimated from body surface area, consistent with the expected behaviour of a molecule of mass $115,135 \mathrm{D}$, and indicating that CRP is predominantly intravascular.

Clearance and metabolic analysis of ${ }^{125}$ I-CRP in patients with inflammatory and noninflammatory disease. In 5 patients with active RA, who had a median circulating CRP concentration of $59 \mathrm{mg} /$ liter (range 13-152), the plasma turnover of ${ }^{125}$ I-CRP did not differ significantly from normal healthy volunteers (Fig. 2). The turnover was also normal in one patient with inactive RA (Table I). The clearance was similarly unaffected in 11 patients with bacterial infections, median plasma CRP concentration $25 \mathrm{mg} /$ liter (range 10-71) (Fig. 2) and

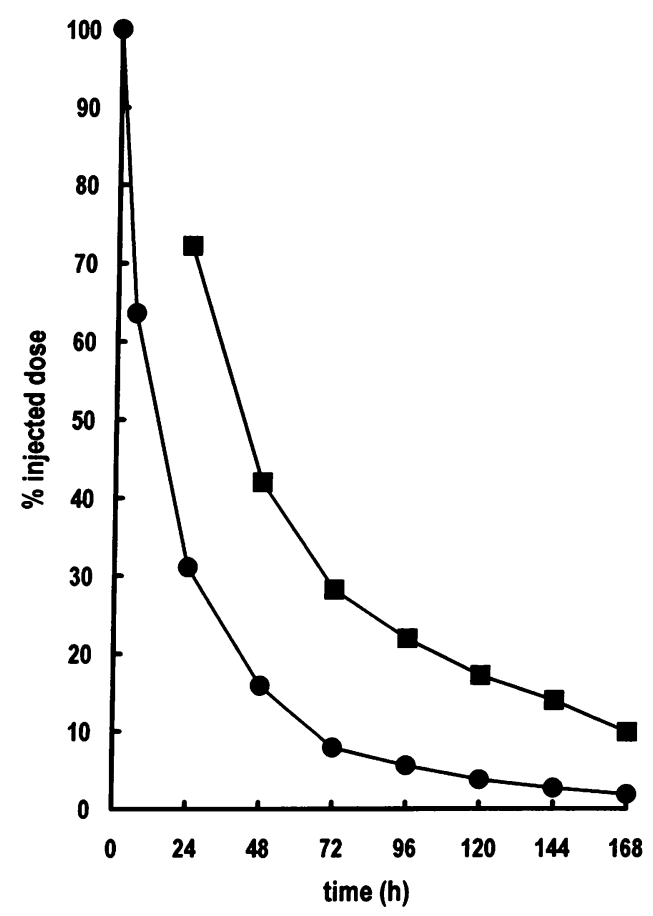

Figure 1. Clearance of ${ }^{125}$ I-human CRP in vivo in normal controls. Each point represents the arithmetic mean of the values in eight healthy normal subjects. The standard deviations fell within the range $0.6-6.4 \%$ for plasma clearance $(\bullet)$, and $4.7-7.1 \%$ for whole body retention ( $\square)$.

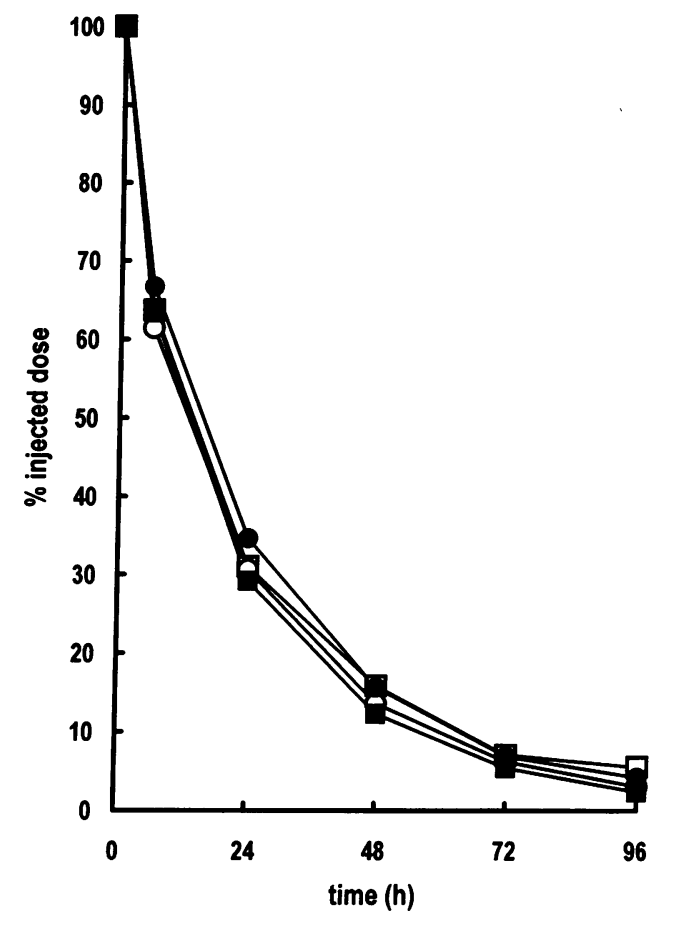

Figure 2. Plasma clearance of ${ }^{125}$ I-human CRP in vivo in patients with inflammatory disease or bacterial infection. Each point represents the arithmetic mean of normal controls or the patients in each group: $\square$, normal controls $(n=8)$; $₫$, active $\operatorname{SLE}(n=5)$; , active rheumatoid arthritis $(n=5)$; $\bullet$, bacterial infection $(n=11)$.

remained constant in two cases who were restudied after successful treatment and normalization of CRP levels (not shown). In active SLE uncomplicated by infection the circulating CRP concentration is often within normal limits and is rarely more than modestly elevated (34). It was therefore of particular interest that plasma clearance of ${ }^{125}$ I-CRP was normal, both in five patients with active disease and no elevation of CRP level (Fig. 2) and in one patient with an intercurrent bacterial infection and a plasma CRP concentration of $56 \mathrm{mg} /$ liter (Table I). The volume of distribution for the tracer was not increased in any of the patients, excluding first pass extravascular localization.

This constancy of CRP turnover was confirmed in four patients with, respectively, active polymyositis, active SLE overlap syndrome, inactive polyarteritis and Crohn's disease with AA amyloidosis and in five individuals with malignant neoplasia (Table I). The fractional catabolic rate of CRP was thus independent of the plasma CRP concentration, whilst there was a direct linear relationship between plasma levels and the calculated rate of CRP production (Fig. 3 ). This rate is evidently greatly increased during the acute phase response and may exceed $360 \mathrm{mg} / 24 \mathrm{~h}$.

${ }^{123}$ I-CRP scintigraphy. Scintigraphs were obtained after the intravenous injection of ${ }^{123}$ I-CRP in 10 patients with diseases in which inflammation and tissue damage were prominent, including a patient with active polymyositis and normal CRP and one with active SLE and a raised CRP $(58 \mathrm{mg} / \mathrm{ml})$, possibly related to intercurrent infective pharyngitis. In all these subjects the distribution of tracer activity was confined to the blood pool and no selective tissue or organ localization could be identified (Fig. 4). Despite the administration of potassium 


\begin{tabular}{|c|c|c|c|c|c|}
\hline Subjects & $n$ & Plasma CRP & $\begin{array}{l}\text { Plasma } \\
\text { half-life }\end{array}$ & $\begin{array}{c}\text { Fractional } \\
\text { clearance rate }\end{array}$ & Synthesis rate \\
\hline & & $m g / l i t e r$ & $h$ & $\% / h$ & $\mu g / k g \cdot h$ \\
\hline Normal & 8 & $0.8(0.5)$ & $18.8(3.9)$ & $3.9(0.9)$ & $1.5(1.3)$ \\
\hline \multicolumn{6}{|l|}{ Chronic inflammation } \\
\hline Active RA & 5 & $73(56)$ & $19.0(5.7)$ & $3.9(0.9)$ & $91.9(78.1)$ \\
\hline Inactive RA & 1 & 1 & 19.2 & 3.6 & 2.1 \\
\hline Active SLE & 5 & $3(1)$ & $17.7(2.2)$ & $4.0(0.5)$ & $5.2(2.3)$ \\
\hline Active SLE + infection & 1 & 56 & 14.0 & 4.9 & 112.9 \\
\hline SLE-overlap syndrome & 1 & 1 & 14.8 & 4.7 & 1.9 \\
\hline Polymyositis & 1 & 4 & 16.7 & 4.2 & 6.9 \\
\hline Polyarteritis nodosa & 1 & 9 & 18.9 & 3.8 & 14.6 \\
\hline Crohn's disease & 1 & 14 & 14.5 & 4.8 & 27.7 \\
\hline \multicolumn{6}{|l|}{ Infections } \\
\hline Acute bacterial infection & 9 & $31(20)$ & $19.9(2.8)$ & $3.6(0.6)$ & $43.4(28.4)$ \\
\hline Chronic osteomyelitis & 2 & $22(13)$ & $18.4(0.4)$ & $3.8(0.1)$ & $25.3(14.7)$ \\
\hline \multicolumn{6}{|l|}{ Neoplasia } \\
\hline With APR & 3 & $62(61)$ & $16.9(4.5)$ & $4.3(1.1)$ & $103.4(80.7)$ \\
\hline No APR & 2 & $3(0)$ & $26.9(8.2)$ & $2.8(0.8)$ & $3.5(1.5)$ \\
\hline
\end{tabular}

Values are given as mean (SD). One-way analysis of variance comparing $t_{1 / 2}$ in each of the main disease groups (chronic inflammation, bacterial infection, neoplasia) with the normal controls gave $F=1.052, P=0.382$.

iodide, minor uptake of radioactivity was occasionally seen in the salivary glands, thyroid, and stomach. This nonspecific localization reflects the known distribution of free radioiodine, and quantitatively represented $<1 \%$ of the injected radioactivity.

\section{Discussion}

These studies are the first to describe the in vivo turnover and distribution of human CRP in man in health and disease. The CRP used, unlike that in all previous reported work on human CRP, was isolated from the serum of a single normal healthy donor. This was essential, on ethical grounds, to avoid any risk of transmissible disease. The radioiodinated protein retained in full its normal structure and ligand-binding properties in vitro. Furthermore, the labeled CRP was handled in vivo in laboratory animals in a manner identical to purified human CRP which had not been labeled, and to completely untreated CRP administered by injection of whole acute phase human serum. In that there is no evidence for polymorphism of either the gene coding sequence for human CRP or the protein itself, the behavior of the labeled isologous tracer can be confidently taken to reflect that of autologous CRP in the body.

In normal subjects clearance of CRP from the plasma was monoexponential with a biological half-time of $19 \mathrm{~h}$, indicating extremely rapid turnover compared with the majority of plasma proteins. This finding is consistent with previous observations that elevated circulating levels of CRP fall by up to $50 \%$ per day when the acute-phase stimulus resolves (35). In several individuals $100 \%$ of the injected radioactivity was recovered in the urine after $7 \mathrm{~d}$ indicating that there was no localization and/or sequestration of the labeled protein. Slightly lower rates of recovery in other subjects probably reflect minor loss of radioactivity via the gastrointestinal tract, which accounts for up to $5 \%$ in turnover studies of other radioiodinated plasma proteins. In the one normal and two patients in whom it was sought there was no uptake/binding to blood cells. Analysis of the single compartment model used here suggests that $\sim 30 \%$ of CRP is extravascular, though in free equilibrium with the plasma pool, and is consistent with the expected behavior of a molecule of mass $115,135 \mathrm{D}$.

Amongst patients studied with a variety of inflammatory and neoplastic conditions, resulting in elevated levels of circu-

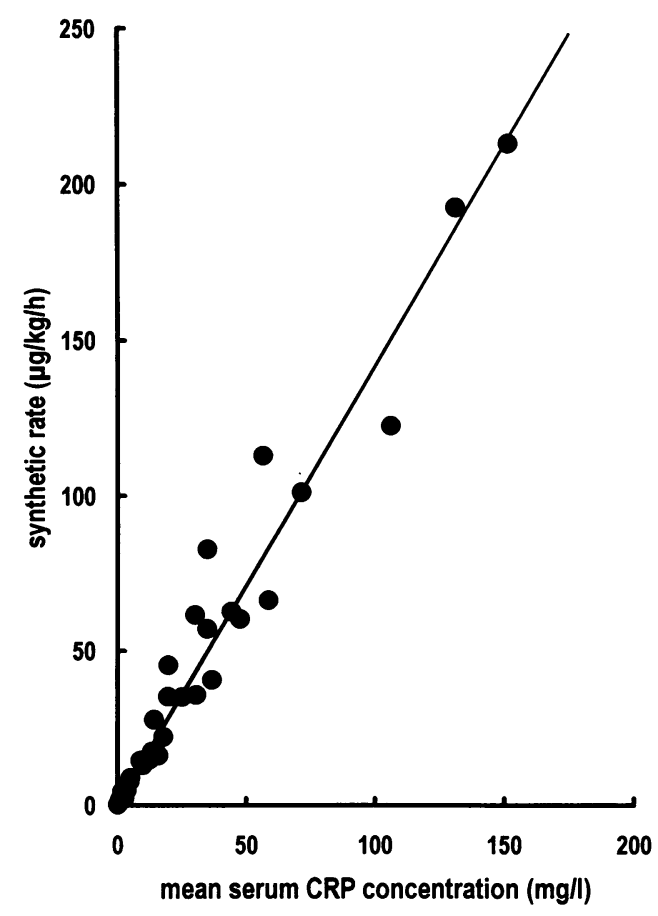

Figure 3. Relationship between mean serum CRP concentration in each individual during the period of study and the estimated rate of synthesis. Linear regression analysis: $r=0.98$, slope $=1.39, n=42$. 

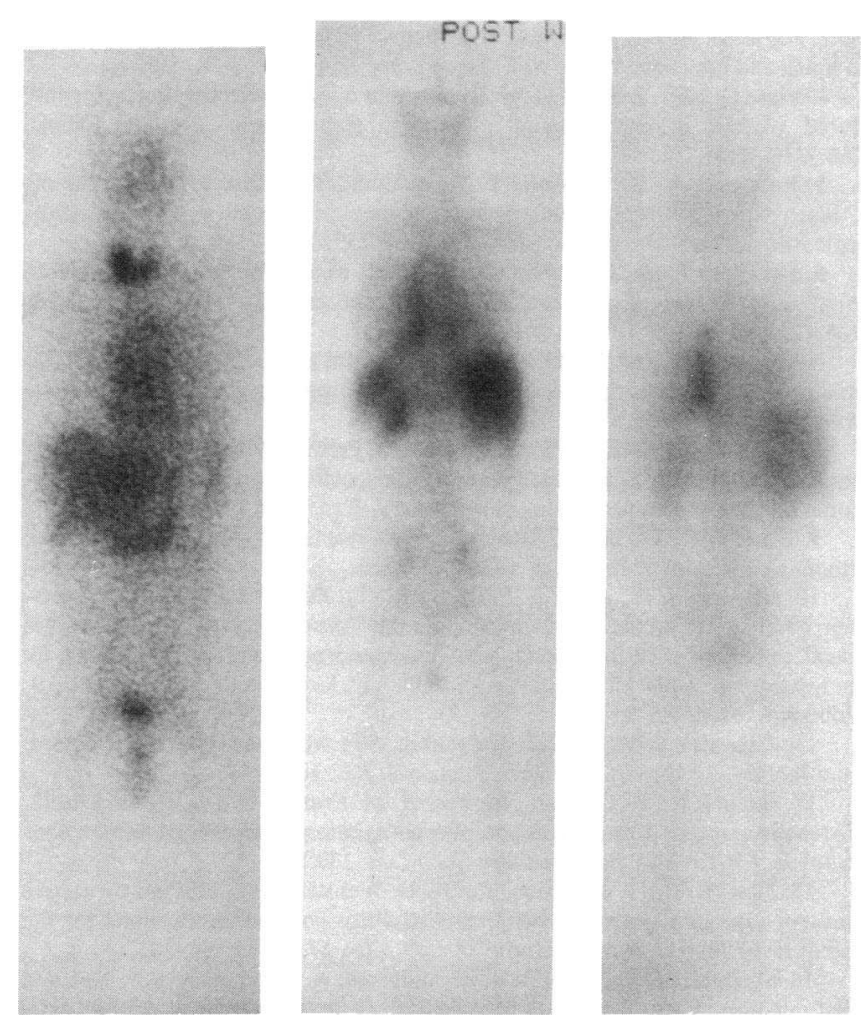

Figure 4. Whole-body scintigraphs after iv injection of ${ }^{123}$ I-human CRP. Left: Anterior image at $24 \mathrm{~h}$ of a patient with right lower lobe pneumococcal pneumonia showing distribution of isotope in the blood pool only with no localization to the site of infection. Activity seen in the thyroid and stomach represents uptake of traces of free radioiodine, whilst the bladder contains excreted breakdown products of the labeled protein. Middle: Posterior image at $6 \mathrm{~h}$ of a patient with a postoperative left psoas abscess showing normal blood pool distribution with signal from the liver, spleen, heart and kidneys. There is no signal from the site of the lesion. Right: Posterior image at $6 \mathrm{~h}$ of a patient with myeloma and extensive hepatic and renal $\mathrm{AL}$ amyloidosis who had previously undergone splenectomy. Tracer is distributed in the blood pool only.

lating CRP and in whom there was likely to be an abundance of the putative ligands with which CRP might interact, there were no differences in the turnover and clearance of ${ }^{125}$ I-CRP. Results for the plasma half-life, fractional catabolic rate directly measured from the urinary excretion of radioactivity, and whole-body retention of radioactivity after $7 \mathrm{~d}$ were identical to normal controls, indicating that there was no substantial sequestration or altered handling of CRP in these disease states. In two patients with infections, who were studied both during the acute phase of the illness and subsequently when serum CRP levels had normalized, identical turnover profiles were obtained. Similarly, no differences were observed in patients with active SLE and polymyositis, in whom characteristically normal circulating levels of CRP were present.

The failure of patients with SLE and with polymyositis to mount a marked serum acute phase response of CRP to the inflammation and tissue damage caused by these diseases themselves is thus due to failure of CRP production rather than accelerated clearance, and the same is likely to be true of the few other disorders which show the same limited CRP response: scleroderma, Sjögren's disease, ulcerative colitis, and leukemia $(1,2)$. CRP measurements are not useful for monitoring uncomplicated disease activity in these particular disorders, but, as previously reported, they can make a vital contribution to diagnosis and management of intercurrent infection in such patients $(34,36)$. In contrast, demonstration that the only significant determinant of plasma CRP levels is the rate of synthesis importantly validates the clinical use of serum CRP measurements to monitor disease activity in all other disorders which are characterized by a major acute phase response, in that the production rate of CRP in each individual is likely to reflect the presence, extent and activity of disease. Although this is presumably true also for the production rates of other acute-phase proteins, such as clotting factors, complement proteins, proteinase inhibitors, and transport proteins, their clearance, in contrast to that of CRP, is dramatically affected by the activation and/or complex formation involved in their physiological functions. Their plasma levels are therefore not reliable as indices of the acute phase response itself.

The present findings with human CRP in man confirm previous work in experimental animals in which the clearance of both isologous and heterologous CRP was rather constant and generally independent of plasma CRP concentration. Although we have previously reported a negative correlation between fractional catabolic rate and autologous plasma CRP concentration in rabbits which had received subcutaneous casein injections (32), this was not observed in animals which were undergoing a naturally occurring acute phase response, nor was it found by others (31). CRP clearance was also unaffected by the intravascular presence of even macromolecular ligands to which CRP binds, such as apoB-containing lipoproteins (in the rabbit) or pneumococcal C-polysaccharide (32, 33). Formation of CRP-ligand complexes in the circulation thus does not accelerate CRP clearance, which apparently proceeds under all circumstances at a constant maximum rate via a mechanism which is apparently not saturable. This does not preclude the possibility that CRP binding may modulate the rate and / or site of clearance of ligands compared with their fate in the absence of CRP. Indeed human CRP passively administered to mice alters in favour of the spleen the balance of splenic and hepatic uptake of pneumococci, of C-polysaccharide-coated mouse erythrocytes and of free $\mathrm{C}$-polysaccharide, although the overall blood clearance rate of these ligands is not affected $(3,33,37,38)$. However, we have previously found no evidence for the presence of significant amounts of CRP complexed with any macromolecular ligand in acute phase sera from patients with various infections, inflammatory and neoplastic conditions $(39,40)$.

A possible role of CRP in recognizing and binding to materials exposed in sites of inflammation and tissue damage, suggested by in vitro studies of CRP binding (41) is not supported by our results. Scintigraphy with ${ }^{123}$ I-labeled CRP in 10 individuals with localized and systemic infective, inflammatory and neoplastic conditions failed to demonstrate any tissue localization of labeled CRP. Using the analogy of ${ }^{123}$ I-SAP localization in amyloidosis $(27,30)$, focal deposition of as little as $1 \%$ of the injected material might have been detected using these methods. As expected from in vitro ligand binding studies and in vivo studies in experimental murine amyloid (42) there was no localization of isologous CRP to amyloid deposits in two individuals with well documented extensive systemic $\mathrm{AA}$ and $\mathrm{AL}$ amyloidosis, respectively. Interestingly, there was no discernible localization of ${ }^{123}$ I-CRP to the affected lung in a patient 
with pneumococcal lobar pneumonia indicating that the $\mathrm{C}$ polysaccharide of the causative organism was either not available, or not sufficiently abundant in the tissues. Although there have been a few reports of the variable presence of immunohistochemically detectable CRP in inflammatory and/or necrotic tissue lesions (43-50), inappropriate fixation and staining techniques have sometimes been used $(48,49)$ or essential controls for immunological specificity omitted (48). Significant CRP is present only rarely at sites of inflammation per se, although it definitely does appear in small amounts on frankly necrotic muscle fibres in cardiac or skeletal muscle damaged by extreme experimental procedures $(3,43,44,50)$. The present failure to detect significant tissue deposition of ${ }^{123}$ I-CRP in any of the various pathologies studied is therefore compatible with the paucity of convincing immunohistochemical evidence, but we cannot exclude the possibility that avid binding of autologous CRP to potential tissue ligands at an early stage of disease may have blocked their subsequent availability for interaction with the tracer.

Among previous speculations about the function of CRP, the results reported here are most consistent with the original suggestion of Pepys (1) that CRP acts to bind and thereby neutralize or "detoxify" harmful substances which gain access to the circulation. Such substances may be of extrinsic, microbial origin, like $\mathrm{C}$-polysaccharide and related materials, which are widely distributed in nature, or of autologous origin. For example, CRP efficiently blocks the biological activity of the potent phosphocholine-containing inflammatory mediator, PAF (4, 51, 52). CRP also binds to lysophospholipids (53) and may prevent their damaging effects $(4,51,52)$. Furthermore, CRP may block the phospholipase activities which provide substrates for the cyclo and lipooxygenase pathways (4). Interesting preliminary data from mice transgenic for rabbit CRP show that the presence of this xenogeneic CRP, in a species which produces very little of its own CRP, efficiently protects the animals from endotoxin lethality and that the mechanism of this protection is largely via inactivation of $\operatorname{PAF}(54,55)$. A major role of CRP may therefore be to bind and neutralize PAF and other biologically active phospholipid ligands in plasma and tissue fluids. Raised concentrations of CRP are present in conditions likely to be associated with increased production and/or release of such mediators and may thereby serve to control their effects. The rabbit CRP transgenic mice are also apparently protected against C5a-induced alveolitis (56), and a further role of CRP and/or its fragments in modulating chemotaxis and activity of neutrophils (11-14) would be compatible with the present findings of unvarying clearance and lack of tissue deposition of CRP in humans.

\section{Acknowledgments}

We wish to thank our colleagues at Hammersmith Hospital for referring some of the patients studied, Ms. Suzanne Richardson for technical assistance and Ms. Beth Sontrop for expert secretarial assistance.

The work was supported by grants from the Medical Research Council, the Wellcome Trust and the Arthritis \& Rheumatism Council for Research.

\section{References}

1. Pepys, M. B. 1981. C-reactive protein fifty years on. Lancet. $i: 653-656$. 2. Pepys, M. B., and M. L. Baltz. 1983. Acute phase proteins with special reference to $\mathrm{C}$-reactive protein and related proteins (pentaxins) and serum amyloid A protein. Adv. Immunol. 34:141-212.
3. Pepys, M. B., I. F. Rowe, and M. L. Baltz. 1985. C-reactive protein: binding to lipids and lipoproteins. Int. Rev. Exp. Pathol. 83-111.

4. Vigo, C. 1985. Effect of C-reactive protein on platelet-activating factor-induced platelet aggregation and membrane stabilization. J. Biol. Chem. 260:3418-3422.

5. Robey, F. A., K. D. Jones, T. Tanaka, and T.-Y. Liu. 1984. Binding of C-reactive protein to chromatin and nucleosome core particles: a possible physiologic role of C-reactive protein. J. Biol. Chem. 259:7311-7316.

6. Du Clos, T. W., L. Marnell, L. R. Zlock, and R. W. Burlingame. 1991. Analysis of the binding of C-reactive protein to chromatin subunits. J. Immunol. 146:1220-1225.

7. Pepys, M. B., and P. J. G. Butler. 1987. Serum amyloid P component is the major calcium-dependent specific DNA binding protein of the serum. Biochem. Biophys. Res. Commun. 148:308-313.

8. Butler, P. J. G., G. A. Tennent, and M. B. Pepys. 1990. Pentraxin-chromatin interactions: serum amyloid $P$ component specifically displaces H1-type histones and solubilizes native long chromatin. J. Exp. Med. 172:13-18.

9. Du Clos, T. W. 1989. C-reactive protein reacts with the U1 small nuclear ribonucleoprotein. J. Immunol. 143:2553-2559.

10. Kaplan, M. H., and J. E. Volanakis. 1974. Interaction of C-reactive protein complexes with the complement system. I. Consumption of human complement associated with the reaction of C-reactive protein with pneumococcal Cpolysaccharide and with the choline phosphatides, lecithin and sphingomyelin. $J$. Immunol. 112:2135-2147.

11. Kilpatrick, J. M., and J. E. Volanakis. 1991. Molecular genetics, structure, and function of C-reactive protein. Immunol. Res. 10:43-53.

12. Buchta, R., R. Gennaro, M. Pontet, M. Fridkin, and D. Romeo. 1988. C-reactive protein decreases protein phosphorylation in stimulated human neutrophils. FEBS (Fed. Eur. Biochem. Soc.) Lett. 237:173-177.

13. Kew, R. R., T. M. Hyers, and R. O. Webster. 1990. Human C-reactive protein inhibits neutrophil chemotaxis in vitro: possible implications for the adult respiratory distress syndrome. J. Lab. Clin. Med. 115:339-345.

14. Shephard, E. G., S. M. Beer, R. Anderson, A. F. Strachan, A. E. Nel, and F. C. de Beer. 1989. Generation of biologically active C-reactive protein peptides by a neutral protease on the membrane of phorbol myristate acetate-stimulated neutrophils. J. Immunol. 143:2974-2981.

15. Mold, C., S. Nakayama, T. J. Holzer, H. Gewurz, and T. W. Du Clos. 1981. C-reactive protein is protective against Streptococcus pneumoniae infection in mice. J. Exp. Med. 154:1703-1708.

16. Yother, J., J. E. Volanakis, and D. E. Briles. 1982. Human C-reactive protein is protective against fatal Streptococcus pneumoniae infection in mice. $J$. Immunol. 128:2374-2376.

17. Shine, B., F. C. de Beer, and M. B. Pepys. 1981. Solid phase radioimmunoassays for C-reactive protein. Clin. Chim. Acta. 117:13-23.

18. Heinrich, P. C., J. V. Castell, and T. Andus. 1990. Interleukin-6 and the acute phase response. Biochem. J. 265:621-636.

19. de Beer, F. C., and M. B. Pepys. 1982. Isolation of human C-reactive protein and serum amyloid P component. J. Immunol. Methods. 50:17-31.

20. Pontet, M., R. Engler, and M. F. Jayle. 1978. One step preparation of both human C-reactive protein and Clt. FEBS (Fed. Eur. Biochem. Soc.) Lett. 88:172178.

21. McDougal, J. S., L. S. Martin, S. P. Cort, M. Mozen, C. M. Heldebrant and B. L. Evatt. 1985. Thermal inactivation of the acquired immunodeficiency syndrome virus, human T lymphotropic virus-III/lymphadenopathy-associated virus, with special reference to antihemophilic factor. J. Clin. Invest. 76:875-877.

22. Poulter, L., B. N. Green, S. Kaur, and A. L. Burlingame. 1990. The characterisation of native and recombinant proteins by electrospray mass spectrometry. In Biological Mass Spectrometry. A. L. Burlingame, and J. A. McCloskey, editors. Elsevier Science Publishers B. V., Amsterdam. 119-128.

23. Lei, K.-J., T. Lin, G. Zon, E. Soravia, T.-Y. Liu, and N. D. Goldman 1985. Genomic DNA sequence for human C-reactive protein. J. Biol. Chem. 260:13377-13383.

24. Woo, P., J. R. Korenberg, and A. S. Whitehead. 1985. Characterization of genomic and complementary DNA sequence of human C-reactive protein, and comparison with the complementary DNA sequence of serum amyloid $P$ component. J. Biol. Chem. 260:13384-13388.

25. Oliveira, E. B., E. C. Gotschlich, and T.-Y. Liu. 1977. Primary structure of human C-reactive protein. Proc. Natl. Acad. Sci. USA. 74:3148-3151.

26. Mather, S. J., and B. G. Ward. 1987. High efficiency iodination of monoclonal antibodies for radiotherapy. J. Nucl. Med. 28:1034-1036.

27. Hawkins, P. N., M. J. Myers, J. P. Lavender, and M. B. Pepys. 1988. Diagnostic radionuclide imaging of amyloid: biological targeting by circulating human serum amyloid P component. Lancet. $i: 1413-1418$.

28. Fagan, E. A., R. F. Dyck, P. N. Maton, H. J. F. Hodgson, V. S. Chadwick and M. B. Pepys. 1982. Serum levels of C-reactive protein in Crohn's disease and ulcerative colitis. Eur. J. Clin. Invest. 12:351-360.

29. Wasunna, A., A. Whitelaw, R. Gallimore, P. N. Hawkins, and M. B. Pepys. 1990. C-reactive protein and bacterial infection in preterm infants. Eur. $J$. Pediatr. 149:424-427. 
30. Hawkins, P. N., J. P. Lavender, and M. B. Pepys. 1990. Evaluation of systemic amyloidosis by scintigraphy with ${ }^{123}$ I-labeled serum amyloid $\mathrm{P}$ component. N. Engl. J. Med. 323:508-513.

31. Chelladurai, M., S. S. Macintyre, and I. Kushner. 1983. In vivo studies of serum C-reactive protein turnover in rabbits. J. Clin. Invest. 71:604-610.

32. Rowe, I. F., M. L. Baltz, A. K. Soutar, and M. B. Pepys. 1984. In vivo turnover studies of C-reactive protein and lipoproteins in the rabbit. Clin. Exp. Immunol. 58:245-252.

33. Baltz, M. L., I. F. Rowe, and M. B. Pepys. 1985. In vivo turnover studies of C-reactive protein. Clin. Exp. Immunol. 59:243-250.

34. Pepys, M. B., J. G. Lanham, and F. C. de Beer. 1982. C-reactive protein in systemic lupus erythematosus. In Systemic Lupus Erythematosus. Clin. Rheum. Dis. 8:91-103.

35. Cox, M. L., A. G. Rudd, R. Gallimore, H. M. Hodkinson, and M. B. Pepys. 1986. Real-time measurement of serum C-reactive protein in the management of infection in the elderly. Age Ageing. 15:257-266.

36. Starke, I. D., F. C. de Beer, P. J. Donnelly, D. Catovsky, J. M. Goldman, D. G. Galton, and M. B. Pepys. 1984. Serum C-reactive protein levels in the management of infection in acute leukaemia. Eur. J. Cancer 20:319-325.

37. Nakayama, S., C. Mold, H. Gewurz, and T. W. Du Clos. 1982. Opsonic properties of C-reactive protein in vivo. J. Immunol. 128:2435-2438.

38. Nakayama, S., H. Gewurz, T. Holzer, T. W. Du Clos, and C. Mold. 1983. The role of the spleen in the protective effect of C-reactive protein in Streptococcus pneumonial infection. Clin. Exp. Immunol. 54:319-326.

39. de Beer, F. C., B. Shine, and M. B. Pepys. 1982. Radiometric ligand binding assay for $\mathrm{C}$-reactive protein: complexed $\mathrm{C}$-reactive protein is not detectable in acute phase serum. Clin. Exp. Immunol. 50:231-237.

40. de Beer, F. C., A. K. Soutar, M. L. Baltz, I. Trayner, A. Feinstein, and M. B. Pepys. 1982. Low density and very low density lipoproteins are selectively bound by aggregated C-reactive protein. J. Exp. Med. 156:230-242.

41. Volanakis, J. E. 1982. Complement activation by C-reactive protein complexes. Ann. NY Acad. Sci. 389:235-250.

42. Hawkins, P. N., M. J. Myers, A. A. Epenetos, D. Caspi, and M. B. Pepys. 1988. Specific localization and imaging of amyloid deposits in vivo using ${ }^{123} \mathrm{I}-\mathrm{la}$ beled serum amyloid P component. J. Exp. Med. 167:903-913.

43. Kushner, I., and M. H. Kaplan. 1961. Studies of acute phase protein. I. An immunohistochemical method for the localization of Cx-reactive protein in rabbits. Association with necrosis in local inflammatory lesions. J. Exp. Med. 114:961-973.
44. Kushner, I., L. Rakita, and M. H. Kaplan. 1963. Studies of acute phase protein. II. Localization of $\mathrm{Cx}$-reactive protein in heart in induced myocardial infarction in rabbits. J. Clin. Invest. 42:286-292.

45. Parish, W. E. 1976. Studies in vasculitis. VII. C-reactive protein as a substance perpetuating chronic vasculitis: occurrence in lesions and concentrations in sera. Clin. Allergy. 6:543-550.

46. Gitlin, J. D., I. Gitlin, and D. Gitlin. 1977. Localization of C-reactive protein in synovium of patients with rheumatoid arthritis. Arthritis Rheum. 20:1491-1499.

47. Du Clos, T. W., C. Mold, P. Y. Paterson, J. Alroy, and H. Gewurz. 1981. Localization of C-reactive protein in inflammatory lesions of experimental allergic encephalomyelitis. Clin. Exp. Immunol. 43:565-573.

48. Rodrigues, M. M., and P. G. Robey. 1982. C-reactive protein in human lattice corneal dystrophy. Curr. Eye Res. 2:721-724.

49. Reynolds, G. D., and R. P. Vance. 1987. C-reactive protein immunohistochemical localization in normal and atherosclerotic human aortas. Arch. Pathol. Lab. Med. 111:265-269.

50. Rowe, I. F., L. N. Walker, D. E. Bowyer, A. K. Soutar, L. C. Smith, and M. B. Pepys. 1985. Immunohistochemical studies of C-reactive protein and apolipoprotein B in inflammatory and arterial lesions. J. Pathol. 145:241-249.

51. Filep, J., and E. Foldes-Filep. 1989. Effects of C-reactive protein on human neutrophil granulocytes challenged with $\mathrm{N}$-formyl-methionyl-leucyl-phenylalanine and platelet-activating factor. Life Sci. 44:517-524.

52. Filep, J. G., F. Herman, E. Kelemen, and E. Foldes-Filep. 1991. C-reactive protein inhibits binding of platelet-activating factor to human platelets. Thromb. Res. 61:411-421.

53. Volanakis, J. E., and K. W. A. Wirtz. 1979. Interaction of C-reactive protein with artificial phosphatidylcholine bilayers. Nature (Lond.). 281:155157.

54. Xia, D., C. Lin, J. Yun, T. Wagner, T. Magnuson, and D. Samols. 1991. Transgenic mice expressing rabbit C-reactive protein (CRP) resist endotoxemia. FASEB J. 5:1628. (Abstr.)

55. Xia, D., and D. Samols. 1992. Protective effect of rabbit C-reactive protein (RAB-CRP) against mediators of septic shock in transgenic mice. FASEB J. 6:1344. (Abstr.)

56. Heuertz, R. M., D. Xia, D. Samols, and R. O. Webster. 1992. Transgenic mice expressing plasma rabbit $\mathrm{C}$-reactive protein exhibit diminished vascular permeability and neutrophil infiltration in C5a-induced alveolitis. FASEB J. 6:1064. (Abstr.) 